\title{
Comparison of spinal manipulation and short-wave diathermy on patients with chronic postural low back pain, in department of physical medicine at teaching hospital, Kandy, Sri Lanka
}

\author{
W. A. T. Nisansala, H. H. T. Shashikala, I. N. Aluthge, K. N. B. Illukkumbura, \\ S. Sukirthan, J. M. K. B. Jayasekara*
}

Department of Physiotherapy, Faculty of Allied Health Sciences, Kothelawala Defence University, Sri Lanka

Received: 08 June 2021

Revised: 16 July 2021

Accepted: 21 July 2021

*Correspondence:

Dr. J. M. K. B. Jayasekara,

E-mail: kbjayasekara@gmail.com

Copyright: (c) the author(s), publisher and licensee Medip Academy. This is an open-access article distributed under the terms of the Creative Commons Attribution Non-Commercial License, which permits unrestricted non-commercial use, distribution, and reproduction in any medium, provided the original work is properly cited.

\begin{abstract}
Background: Chronic postural low back pain (CPLBP) is one of the common health problems worldwide. The aim of the study was to compare the spinal manipulation (SM) and short-wave diathermy (SWD) in patients with CPLBP in department of physical medicine at teaching hospital, Kandy, Sri Lanka.

Methods: Observational study was conducted. Patients diagnosed as CPLBP, who referred to the department of physical medicine (DPM), teaching hospital Kandy, were observed in the study $(n=140)$. Seventy (70) patients were allocated for SWD and 70 for SM by the consultant. Two physiotherapists were routinely appointed for the treatments and SWD treatment by group 1 and SM was carried out by group 2 . The two treatment sessions were continued once a week through four weeks. Outcomes were measured by numerical pain scale to compare with initial pain.

Results: Group 1, SM consisted 39 females and 31 males, group 2, SWD 40 females and 30 males. After 4 sessions, the mean value of pain reduction from initial pain was significantly high $(p<0.001)$ in SM group than the short-wave diathermy group in both genders. (Female: 6.410 (SM) and 4.625 (SWD), Male:6.710 (SM) and 4.333 (SWD). Further the mean values showed that there was a significant pain reduction during the initial treatment session than $2^{\text {nd }}, 3^{\text {rd }}$ and final sessions in both treatment groups.

Conclusions: Pain reduction was more pronounced in the first treatment session in both methods. SM is more effective for the treatment of CPLBP irrespectively the age and gender when compare to the SWD in the study population. Therefore, SM could apply on CPLBP patients with higher effective treatment.
\end{abstract}

Keywords: CPLBP, SWD, SM, Pain reduction

\section{INTRODUCTION}

Chronic postural low back pain (CPLBP) is a common health problem worldwide and a major cause of disability. It mainly interferes with work performance and quality of life. ${ }^{1}$ The world health organization has listed it in the top ten conditions with the highest disease burden on society. It is estimated that in all populations about eighteen percent of the people will experience low back pain at any given time. Chronic low back pain prevalence was $4.2 \%$ in individuals aged between 24 and 39 years old and $19.6 \%$ in those aged between 20 and $59 .^{2}$

Back pain is a symptom rather than a disease. Low back pain is defined as "neither a disease nor a diagnostic entity of any sort and the term refers to pain of variable duration in an area of the anatomy afflicted so, often that it has become a paradigm of responses to external and internal stimuli". ${ }^{3}$ 
Low back pain is one of the most common reasons for medical consultation and it affects people of all ages.The prevalence rate for children and adolescents is lower than that seen in adults but it is rising. ${ }^{4}$ Prevalence increases and peaks between the ages of thirty five and fifty five. ${ }^{1}$ Low back pain is the leading cause of activity limitation and work absence throughout much of the world, imposing a high economic burden on individuals, families, communities, industry, and governments. ${ }^{5}$ Several studies have been performed in Europe to evaluate the social and economic impact of low back pain. In the United Kingdom, low back pain has identified as the most common cause of disability in young adults, with more than 100 million workdays lost per year. ${ }^{6}$ In the US an estimated 149 million work days are lost every year because of low back pain. ${ }^{7}$ In Sri Lanka there were not any specific studies concerning the prevalence of CPLBP and the incidence of economic impact.

Law back pain can be divided into two major categories as postural/mechanical low back pain and the structural low back pain. This study concerns about the postural/mechanical low back pain which is also referred to as nonspecific low back pain. Non-specific low back pain is tension, soreness and or stiffness in the lower back region for which it is not possible to identify a specific cause of the pain. Several structures in the back including the joints, discs and the connective tissues may contribute to the symptoms. Postural low back pain was in medical no man's land for past decades but the behaviour of it has been identified by physical therapists.

Low back pain can be divided as acute, sub-acute or chronic based on the time period. This study concerns the chronic low back pain which lasts for more than three months. There are so many causes for low back pain in medical literature. Neurological, vascular, musculoskeletal and psychosocial factors mainly contribute to low back pain has mentioned eleven causes for back pain. ${ }^{8}$ They are aging and degenerative changes, degeneration of the disc, degeneration of the joints and ligaments, stomach ulcers and indigestion, obesity, bad posture, sudden blow to the spine, lifting heavy objects and exercising without warming up. Back pain can be a result of intervertebral disc prolapse due to unbearable weight lifting or chronic degenerative changes. There is no clearly identifiable obvious cause for postural low back pain and it has seemed some mechanical and structural problems cause pain in low back. Stiffness of intervertebral and zygapophyseal joints mainly contributes to CPLBP. Fibrositis and trigger point formation in vulnerable muscles are also highly considerable causes for chronic postural law back pain.

Exercise therapy, electrotherapy, mobilization and SM are some of the treatment methods to treat low back pain. SM is used by some physical therapists as successful treatment for CPLBP with all the other conventional interventions. ${ }^{9}$ The international federation of orthopedic manipulative physical therapists define manual therapy technique as a passive high velocity low amplitude thrust applied to a joint complex within its anatomical limit with the intent to restore optimal motion, function and/or reduce pain. SM was well recognized by Sir James Cyriax (1960) and it was further developed by Maitland. He developed an accessory movement grading system which contains from grade one to five. According to that Maitland grade five mobilization is synonymous with manipulation.

Among conventional treatment methods electrotherapy, especially SWD is frequently used. ${ }^{10}$ But it is time consuming and the equipment are of high cost. SWD is the therapeutic elevation of temperature in the tissues by means of an oscillating electric current of extremely high frequency. ${ }^{11}$ Temperature elevation leads to increased metabolic activity, increased blood flow and stimulates neural receptors in skin or tissues and therefore assists the healing process. When comparing SWD with SM, there are number of hazards and contraindications. Excess current and concentration of electric field are the main factors which contribute to occur burns and electric shock could result from contact with the casing of the apparatus. Hemorrhages, venous thrombosis or phlebitis, arterial disease, pregnancy, plates and pace makers, disturbed skin sensation, tumours are list of contraindications for SWD. Most of the above contraindications could be ignored in SM. For example, SM could be applied without considering the personal factors such as disturbed skin sensation and other vascular disorders. Hazards could hardly occur in the SM. With a highly experienced manual therapist probability of occurring hazards could be minimized to zero percent. Hazards of SM depends only with the personal factors of the therapist, but hazards of SWD depends on both the personal and equipment related factors.

There were many randomized clinical trials regarding SM and SWD. Still there is controversy of effects of SM and SWD in chronic postural law back pain patients. Therefore, this study will be a scope towards the role of SM and SWD for the treatment of CPLBP through organized observation study. And this study was done to compare the effect of SM and Short-Wave Diathermy on patients with CPLBP.

\section{METHODS}

The observational study was conducted among patients who were diagnosed as CPLBP by the consultant orthopedic in the physiotherapy department, teaching hospital Kandy, Sri Lanka during the period of (February2018 to May 2018) 3 months.

Patients in between 25-55 years of age, having CPLBP were included in the study. Patients with tumours in spine and fractures in spine, patients with Ankylosing spondylitis, connective tissue disorders, Potts's disease, Spondylolisthesis, spondylolysis, Cauda Equina syndrome, facet joint osteoarthritis and patients with neurological referred pain, vascular defects and other 
conditions where SMs and SWD are contraindicated were excluded.

Our study observed 140 patients in both groups (SWD and SM) consisted with 70 patients each. Patients who were treated with SWD categorized into group 1 and patients who were treated with SM categorized into group 2. Each treatment was carried out by one trained person throughout the study period to avoid physical errors of the investigator. It is a usual practice conducted at physiotherapy unit. After every treatment session numerical pain scale was given for the analysis of amplitude level of pain and was marked by the patient. Two treatment sessions (SWD and SM) were observed for four weeks period and outcomes were analyzed in terms of numerical pain scale and initial value was taken as the baseline value at the first date of appointment for treatment.

All demographic characteristics and values of numerical pain scale were analyzed and mean (SD), minimum and maximum values were obtained.

Mean values of each patient was used to compare the effect of two treatment methods. All statistical procedures were performed using statistical package for the social sciences (SPSS) version 22. Ethical approval for the study was taken from ethical review committee, teaching hospital Kandy, Sri Lanka.

\section{RESULTS}

Seventy of CPLBP patients were participated to each group (total=140) and among them $57.1 \%(n=40)$ female patients and $42.9 \%(n=30)$ male patients were included to the group $1(\mathrm{SWD})$ and $55.7 \%(\mathrm{n}=39)$ female patients and $44.3 \%(\mathrm{n}=31)$ male patients were included to the group 2 (SM) (Table 1).

The mean age of the female patients in group 1 (SWD) was $42.15(n=40)$ years while 42.57 years $(n=30)$ was the mean age of the male population. The mean age of the female patients in group $2(\mathrm{SM})$ was $41.07(\mathrm{n}=39)$ years while 42.67 years $(n=31)$ was the mean age of the male population (Table 1).

Table 1: Demographic data of all the patients in SWD and SM.

\begin{tabular}{|c|c|c|}
\hline Demographic data & SWD $( \pm$ SD $)$ & SM $( \pm$ SD $)$ \\
\hline No of patients & 70 & 70 \\
\hline No of female patients & 40 & 39 \\
\hline No of Male patients & 30 & 31 \\
\hline $\begin{array}{l}\text { Mean age of female } \\
\text { patients (years) }\end{array}$ & $42.15(8.65)$ & $41.07(9.06)$ \\
\hline $\begin{array}{l}\text { Mean age of male } \\
\text { patients (years) }\end{array}$ & $42.57(8.68)$ & $42.67(9.60)$ \\
\hline
\end{tabular}

Pain reduction during initial, second, third and final sessions in both groups

Paired t test was used to identify the difference the pain reduction during each session in both treatment groups. In group 1 (SWD), mean values of pain reduction in female patients during initial, second, third and final sessions were respectively $3.35,2.21,1.65,1.72$. In the same group, mean values of pain reduction in male patients during initial, second, third and final sessions were respectively 2.77, 2.30, 2.00, and 1.77 (Table 2).

In group $2(\mathrm{SM})$, mean values of pain reduction in female patients during initial, second, $3^{\text {rd }}$ and final sessions were respectively $4.10,2.44,2.08,1.54$. In the same group, mean values of pain reduction in male patients during initial, second, third and final sessions were respectively 4.42, 2.52, 2.06, and 1.16 (Table 2).

However, the mean values illustrated that there was a significant pain reduction during the initial treatment session than $2^{\text {nd }}, 3^{\text {rd }}$ or final sessions between both treatment groups. (Females in SWD: 3.35 (initial) to 2.21/1.65/1.72, males in SWD: 2.77 (initial) to 2.30/2.00/1.77, females in SM: 4.10 (initial) to 2.44/2.08/1.54, males in SM: 4.42 (initial) to $2.52 / 2.06 / 1.16)$.

Table 2: Mean value (SD) of pain reduction from session 1 to 4 in all the patients.

\begin{tabular}{|lllll|}
\hline Variables & Session & Session & Session & Session \\
\hline SWD & $\mathbf{1}$ & $\mathbf{2}$ & $\mathbf{3}$ & $\mathbf{4}$ \\
female & $(2.45$ & 2.21 & 1.65 & 1.72 \\
SWD & 2.77 & $(1.53)$ & $(1.7)$ & $(1.30)$ \\
male & $(2.24)$ & $(2.02)$ & $2(1.64)$ & 1.77 \\
\hline SM & 4.10 & 2.44 & 2.08 & $1.77)$ \\
female & $(3.05)$ & $(2.36)$ & $(2.34)$ & $(2.04)$ \\
\hline \multirow{2}{*}{ SM male } & 4.42 & 2.52 & 2.06 & 1.16 \\
& $(2.53)$ & $(1.79)$ & $(2.38)$ & $(1.46)$ \\
\hline
\end{tabular}

Pain reduction from initial to final session in both treatment groups

Paired t test was again used to compare the means for difference of pain reduction from initial to final session in both treatment groups. In group 1 (SWD), mean value of pain reduction in female patients from initial to final session was 4.625 . In the same group, mean values of pain reduction in male patients from initial to final session was 4.333 (Table 3).

In group $2(\mathrm{SM})$, mean value of pain reduction in female patients from initial to final session was 6.410. In the same group, mean values of pain reduction in male patients from initial to final session was 6.710 (Table 3).

Mean value of pain reduction from initial to final was significantly high in SM group than the SWD group for 
both genders (Female: 6.410 (SM) and 4.625 (SWD), male: 6.710 (SM) and 4.333 (SWD). No significant difference noticed between male and females in each group $(\mathrm{p}>0.05)$.

\section{Table 3: Mean value of pain reduction from initial to} final sessions in both treatments.

\begin{tabular}{|lll|}
$\begin{array}{l}\text { Treatment } \\
\text { method }\end{array}$ & Gender & $\begin{array}{l}\text { Mean value (SD) of pain } \\
\text { reduction from initial to last } \\
\text { session }\end{array}$ \\
\hline \multirow{2}{*}{ SWD } & Female & $4.625(2.28)^{*}$ \\
\cline { 2 - 3 } SM & Male & $4.333(2.41)^{* *}$ \\
\hline & Female & $6.410(2.04)^{*}$ \\
\hline & Male & $6.710(2.74)^{* *}$ \\
\hline
\end{tabular}

$* \mathrm{p}<0.05, * * \mathrm{p}<0.01$

\section{DISCUSSION}

The primary purpose of this study was to compare the effects of SM and SWD low back pain patients. According to the literature there were researches related to SM and other various treatment methods, but SM and SWD for the treatment of CPLBP was not compared in any of them.

Low back pain is considered as an occupational health problem in many developed countries. Due to the lack of knowledge about ergonomics, improper seating and other arrangements are common in Sri Lanka. Sewing machine operators and agricultural workers are most common. ${ }^{12}$ Therefore they tend to show high tendency to get low back pain. This study has recruited the patients in between the ages of 25 to 55 and it is almost similar to the peak age of working population in Sri Lanka as stated in the Sri Lankan among the patients who participated to the clinic. ${ }^{13}$

According to the results of the present study $\mathrm{p}<0.001$ in second, third and final treatment sessions with the initial value of both treatment methods were highly significant. Therefore, it is evident that both of the treatment methods are individually effective for the treatment of CPLBP. These findings are generally consistent with previous theories and research. ${ }^{14}$ Study concluded that the manual thrust manipulation provides greater short-term reductions in self-reported disability and pain scores compared to the usual medical care. ${ }^{15}$ Further confirms the above finding that SM therapy is effective for the treatment of chronic nonspecific LBP. Effectiveness of SWD as an individual treatment method for the chronic low back pain was demonstrated in the past studies. ${ }^{16,17}$

Few of the research studies found which contradict the effectiveness of SM. Systematic reviews of some studies stated SM as a non-effective treatment method. ${ }^{18,19}$

But in our study, mean value was used to analyze further. Mean values of pain reduction in SM is higher than the SWD (Female SM and SWD=4.1>3.35, 2.44>2.21, $2.08>1.65,1.54<1.72 / \mathrm{male} \mathrm{SM}$ and $\mathrm{SWD}=4.42>2.77$, $2.52>2.3, \quad 2.06>2, \quad 1.16<1.77)$. It indicates the improvements of patient's outcome measures in SM compared to the SWD. Therefore, our current study confirms that SM is more effective than the SWD in our study setting.

Sri Lanka is a lower middle-income country, with a wellorganized and expanded health care system. It is divided as to teaching hospitals, provincial general hospitals, district general hospitals, base hospital and divisional hospitals. However uneven distribution of infrastructure and human resources can be clearly seen in between urban and peripheral hospitals. The availability and variation in physical therapist service provision is less marked in the literature addresses the high severity of back pain in rural communities in Sri Lanka. ${ }^{20}$ The study clearly shows how the mode of treatment affect the satisfaction of the patient. It further illustrated that patient with back pain are more satisfied with exercise-based physiotherapy than with passive treatment modalities.

It is clearly showed that low back pain patients are widely spreading all over the country including rural areas. However, SWD machine costs about USD 20000 and many of the peripheral/rural hospitals doesn't have thoseequipment. Due to the lack of supporting literature regarding the effectiveness of SM in Sri Lanka most of the physiotherapists tend to use SWD modality followed by the exercises in order to treat the low back pain patients. In consistent with the conclusion of this study SM could be promoted as an effective treatment method and practicing of manipulation methods among physiotherapists could be addressed. Thus, it will deduct the large number of expenses for such modalities in health care system, in countries similar to Sri Lanka.

In further analysis, the present study mean value of pain reduction is higher in initial treatment session of $\mathrm{SM}$ compared to the final treatment session (/SM=male initial 4.42>1.16 male final/female initial $4.10>1.54$ female final) past study illustrated that number of SM visits had modest effects on chronic low back pain. ${ }^{21}$ Study has found short term effects with SM. But their results cannot be directly compared with our study due to exclusion of men and the inclusion of the patients with degenerative disk disease.

This paper has endeavored to supply enough information about CPLBP and two major treatment methods (SWD and $\mathrm{SM})$ to enable a physiotherapist to assess and set realistic goals of treatment for a person with CPLBP. The use of SWD for the treatment of CPLBP is limited in most hospital settings in Sri Lanka due to the capital cost of machines. We have demonstrated that SM gives results comparable with its conventional procedures (SWD) but at a reduced cost. This will allow more patients to benefit from SM while potentially providing significant cost savings. ${ }^{22}$ To date other than the study of no studies has compared the effectiveness of SM over SWD. 
In future study, sample size should be increased and it would be better to conduct a clinical trial to identify the effectiveness of SM over SWD. Further-more study should be extended by combining it with demographic and other factors.

\section{CONCLUSION}

Both the treatment methods, SWD and SM are individually effective for treating the CPLBP patients. In terms of mean value, greater outcome measures were observed in SM compared to the frequently used SWD for the treatment of CPLBP. SM is more effective for the treatment of CPLBP irrespectively the age and gender when compares to the SWD in the study population. Therefore, SM could apply on CPLBP patients with higher effective treatment even SWD facilities are available. Pain reduction was more pronounced in the first treatment session in both methods.

Funding: No funding sources

Conflict of interest: None declared

Ethical approval: The study was approved by the institutional ethics committee

\section{REFERENCES}

1. Anderson GBJ. The Epidimiology of spinal disorder. The Adult Spine: Principles and Practice. edition. Philadelphia: Lippincott-Raven. 1997.

2. Rodrigo M, Anaclaudia F, Neice F. Prevalence of Chronic Low Back Pain: Systematic Review. Rev Saude Publica. 2015;49:1.

3. Ehrlich GE. Low Back Pain. Bulletin of the World Health Organization. 2003;81(9):671-5.

4. Taimela S, Kujala UM, Salminen JJ, Viljanen T. The prevalence of low back pain among children and adolescents.A nationwide, cohort-based questionnaire survey in Finland. The spine. 1997;22(4):1132-6.

5. Ehrlich GE. Low Back Pain. Bulletin of the World Health Organization. 2003;81(9):671-5.

6. Croft P. The prevalence and characteristics of chronic widespread pain in the general population. J Rheumatol. 1993;20(3):710.

7. Guo HR, Tanaka S, Halperin WE, Cameron LL. Back pain prevalence in US industry and estimates of lost workdays. Am J Public Health. 1999;89(7):1029-35.

8. Mater H. Orthopaedic manual therapy. Vishvaleka Publications; Ratmalana, Sri Lanka. 2014.

9. Clarke TC, Black LI, Stussman BJ, Barnes PM, Nahin RL. Trends in the use of complementary health approaches among adults; United States. National Health Stat Rep. 2015;79:1-16.

10. Foster NE, Thompson KA, Baxter GD, Allen JM. Management of nonspecific low back pain by physiotherapists in Britain and Ireland. A descriptive questionnaire of current clinical practice. Spine. 1999;24(13):1332-42.
11. Foster A, Palastanga N. Clayton's electrotherapy $9^{\text {th }}$ edition. Delhi: AITBS. 2005.

12. Sri Lanka labour demand survey. Department of, Census and Statistics, Ministry of National Policies and Economic Affairs. 2017. Available at: http://repo.statistics.gov.lk/handle/1/756. Accessed on 10 Jan 2021.

13. Sri Lanka labour force survey. Department of, Census and Statistics, Ministry of National Policies and Economic Affairs. 2016;5.

14. Schneider M, Haas M, Glick R, Stevans J, Landsittel D. Comparison of spinal manipulation methods and usual medical care for acute and subacute low back pain: a randomized clinical trial. The spine. 2017;40(4):209-17.

15. Senna MK. Machaly SA. Does maintained spinal manipulation therapy for chronic nonspecific low back pain result in better long-term outcome. Spine. 2011;36(18):1427-37.

16. Ahmed S, Shakoor A, Khan A. Evaluation of the effects of shortwave diathermy in patients with chronic low back pain. Bangladesh med res council bull. 2011;35:18-20.

17. Kerem M, Yigiter K. Effects of continuous and pulsed short-wave diathermy in low back pain. Pain clinic. 2002;14(1):55-9.

18. Ferreira ML, Ferreira PH, Latimer J, Herbert R, Maher CG. Efficacy of spinal manipulation. J manipulative and physiological therapeutics. 2003;26(9):593-601.

19. Rubinstein SM, Van Middelkoop M, Assendelft WJ, De Boer MR, Van Tulder MW. Spinal manipulative therapy for chronic low-back pain: an update of a Cochrane review. Spine. 2011;36(13):825-46.

20. Tennakoon T, Zoysa P. Patient satisfaction with physiotherapy services in an Asian country: Areport from Sri Lanka. Hong Kong Physiotherapy J. 2014;32:2.

21. Oliva-Pascual-Vaca A, Rodriguez-Blanco C, Heredia-Rizo AM, Ricard F, Almazán-Campos G. Short-term effect of spinal manipulation on pain perception, spinal mobility, and full height recovery in male subjects with degenerative disk disease: a randomized controlled trial. Arch physical med rehabilitation. 2014;95(9):1613-9.

22. Gibson T, Harkness J, Blagrave P, Grahame R, Woo P, Hills R. Controlled comparison of Short-Wave Diathermy Treatment with Osteopathic treatment in non-specific low back pain. Lancet, 1987;325(1):1258-61.

Cite this article as: Nisansala WAT, Shashikala HHT, Aluthge IN, Illukkumbura KNB, Sukirthan S, Jayasekara JMKB. Comparison of spinal manipulation and short-wave diathermy on patients with chronic postural low back pain, in department of physical medicine at teaching hospital, Kandy, Sri Lanka. Int J Res Orthop 2021;7:914-8. 